\title{
NUMERICAL ANALYSIS OF GLULAM BEAMS REINFORCED WITH CFRP PLATES
}

\author{
Ivan GLIŠOVIĆa ${ }^{a}$, Marko PAVLOVIĆ ${ }^{b}$, Boško STEVANOVIĆa ${ }^{\text {, Marija TODOROVIĆ }}{ }^{a}$ \\ ${ }^{a}$ Faculty of Civil Engineering, University of Belgrade, Bulevar Kralja Aleksandra 73, 11000 Belgrade, Serbia \\ ${ }^{b}$ Faculty of Civil Engineering and Geosciences, Delft University of Technology, \\ Stevinweg 1, 2628 CN Delft, The Netherlands
}

Received 08 Nov 2016; accepted 20 Apr 2017

\begin{abstract}
This paper presents an analysis of bending behaviour of glued laminated timber (glulam) beams reinforced with carbon fibre reinforced polymer (CFRP) plates, based on finite element numerical modelling. Nonlinear 3-dimensional model was developed and validated by experimental tests carried out on unreinforced beams and beams reinforced with two different reinforcement arrangements. Suitable constitutive relationships for each material were utilised in the model, as well as anisotropic plasticity theory for timber in compression. Adhesive bond between CFRP plate and timber was modelled as a perfect connection. Beam failure in the model was defined by maximum stress criterion. The predicted behaviour of beams has shown good agreement with the experimental results in relation to load-deflection relationship, ultimate load, elastic stiffness and strain profile distribution. The non-linear behaviour of reinforced beams before failure was also achieved in the numerical analysis, confirming the finite element model to be accurate past the linear-elastic range. Experimentally tested reinforced beams usually failed in tensile zone after compressive plasticization of top lamination, which was also simulated in the numerical model. The results proved that the load carrying capacity, stiffness and ductility of glulam beams were successfully increased by addition of CFRP plate at tension side of the section.
\end{abstract}

Keywords: glulam, beam, carbon fibres, reinforcement, bending test, finite element modelling.

\section{Introduction}

Although glued laminated timber (glulam) presents one of the oldest structural engineered wood products, it is still competitive in modern construction industry. The glulam technology provides a variety of unlimited possibilities in terms of shapes and sizes, but its application for longspan and heavily loaded structures is often limited due to relatively low bending strength and stiffness. As a way of upgrading these properties, glulam can be reinforced with fibre reinforced polymer (FRP) composites. The main positive features of FRP composites are excellent mechanical properties, low weight and very good characteristics in relation to durability (Triantafillou 1998), all of which make these materials more appropriate than conventional materials for the reinforcement of timber.

Even though glulam has better characteristics than solid timber, strength reducing flaws (i.e. knots and finger joints in tension zone) often limit its ultimate bending strength. Therefore, the addition of FRP reinforcement with a high tensile strength and high modulus of elasticity in the tension zone of flexural members may improve ultimate load carrying capacity and stiffness, enable ductile compressive failure mode and potentially lower variabil- ity among the properties (Galloway et al. 1996). These advancements make the use of smaller glulam members or even use of lower grades of wood possible.

In the past two decades, numerous researches have applied FRP composites as a structural reinforcement for solid timber and glulam beams, varying the form of reinforcement (plates, sheets, bars, cords) and its placement (externally or internally bonded). The most commonly used fibre types in construction are glass (Gentile et al. 2002; Svecova, Eden 2004; Fiorelli, Dias 2011; Raftery, Harte 2011; Alhayek, Svecova 2012; Raftery, Whelan 2014; Fossetti et al. 2015), carbon (Borri et al. 2005; Micelli et al. 2005; Schober, Rautenstrauch 2007; Kim et al. 2013; D'Ambrisi et al. 2014; Yang et al. 2016a), and aramid (Yahyaei-Moayyed, Taheri 2011). Sustainable natural fibres (basalt, hemp and flex) are becoming the main focus of the latest studies (Borri et al. 2013; de la Rosa et al. 2013; Raftery, Kelly 2015). In order to use the mechanical properties of reinforcement and timber as much as possible, initial prestress of the element by pretensioning the FRP reinforcement has been undertaken (Guan et al. 2005; Kliger et al. 2016; Yang et al. 2016b). Each of research works reported an increase of bending 
strength and stiffness of the beams. The obtained results varied depending on characteristics of the used timber, the type of fibre that forms the composite material, layout of the reinforcement in the element, the reinforcement ratio and the integrity of the bonding surface between FRP and timber (de la Rosa et al. 2013).

Analysing the behaviour of reinforced timber beams in conventional ways asks for extensive experimental testing. If done correctly, numerical modelling can represent cheaper and faster option. In addition, numerical models can even be used to extrapolate beyond the range of test data. Numerical modelling is not always feasible for everyday design, but it is a suitable tool for optimisation of structural performance of reinforced systems. Previous numerical studies have investigated the performance of FRP reinforced timber members mostly using linear or nonlinear finite element models in which the failure criterion was based on strength of materials (Kim, Harries 2010; Nowak et al. 2013; Raftery, Harte 2013). In order to take full advantage of FRP composites as the reinforcement of timber, fracture mechanics concepts were applied (Dourado et al. 2012; Khelifa, Celzard 2014; Khelifa et al. 2015). This approach assumes that the timber failure is a result of the cracks initiation, growth and propagation inside narrow shear bands. However, 3D modelling of complex structures in this way is unsuitable and inefficient (Oudjene, Khelifa 2009).

A focus of this paper is a finite element numerical modelling of glulam beams reinforced with carbon fibre reinforced polymer (CFRP) plates subjected to bending, using software package ABAQUS. Both material and geometrical nonlinearities were introduced in the model which used engineering constants and strength properties as input data. Experimentally obtained results were used for the verification of numerical simulation based on the comparison of load-deflection relationships, stiffness, ultimate load carrying capacities and strain profile distributions. Numerical analysis helped in the interpretation of test results and understanding of the complex stress and strain states in reinforced glulam members.

\section{Experimental work}

Application of CFRP plates as flexural reinforcement of glulam beams was examined in the experimental research conducted at the Faculty of Civil Engineering, University of Belgrade. The experimental program consisted of fabrication and testing of variously reinforced glulam beams. In this section a summary of the experiment on which the numerical modelling was based is given. Further details can be found in Glisović et al. (2016).

\subsection{Materials}

\subsubsection{Glulam}

Tested glulam beams were made from spruce timber (Picea Abies) classified as the strength class C24 according to EN 338:2009. The dimensions of beams were
$80 \times 210 \times 4000 \mathrm{~mm}$, and each beam consisted of seven $30 \mathrm{~mm}$ thick laminations. Best quality laminations were strategically used in the zone of the highest stresses. The phenol-resorcinol adhesive was employed for bonding the laminations.

The material characterization of the timber included tensile, compressive and bending tests according to EN 408:2010. All tests were performed on small clear wood specimens. For the modelling of structural size specimens, the tests results were adjusted according to EN 384:2010. Mechanical properties of timber are given in Table 1. The average moisture content of timber was $11.7 \%$, while the average density was $427 \mathrm{~kg} / \mathrm{m}^{3}$.

Table 1. Mechanical properties for timber obtained from testing

\begin{tabular}{|c|c|}
\hline Material property & Value \\
\hline Compressive strength parallel to grain (MPa) & $36.3(9.8 \%)$ \\
\hline Tensile strength parallel to grain (MPa) & $27.8(25.2 \%)$ \\
\hline Bending strength (MPa) & $42.5(20.6 \%)$ \\
\hline Modulus of elasticity parallel to grain (MPa) & $11,080(12.6 \%)$ \\
\hline
\end{tabular}

\subsubsection{CFRP}

The chosen reinforcement was a pultruded CFRP plate with a cross section of $1.3 \times 60 \mathrm{~mm}$ (trademark Sika CarboDur S613). The plate consisted of unidirectional carbon fibres embedded in an epoxy matrix, with the density of $1.6 \mathrm{~g} / \mathrm{m}^{3}$.

The CFRP material was tested in tension with according to EN ISO 527-5:2009 in order to verify its modulus of elasticity and tensile strength. Tests were carried out with specimens extracted from the plate in the direction of fibres. A modulus of elasticity in tension of $165,543 \mathrm{MPa}$ with coefficient of variation of $2.8 \%$ and tensile strength of $2,846 \mathrm{MPa}$ with coefficient of variation of $4.5 \%$, were determined. These results confirmed the values reported by the manufacturer in the technical data sheet (Sika AG 2013).

\subsubsection{Adhesive}

Two-component, solvent-free, thixotropic adhesives: Resin 1 (for external reinforcement) and Resin 2 (for the internal reinforcement) were used for applying CFRP plates in tension zone of glulam beams. Resin 1 (Sikadur-30) is epoxy paste adhesive, based on a combination of epoxy resins and special filler, and Resin 2 (Sikadur-330) is epoxy based impregnating adhesive. Table 2 gives the properties of epoxy adhesives given by the manufacturer (Sika AG 2014a, 2014b).

\subsection{Beam testing}

Two beam series with different reinforcement arrangements and one unreinforced beam series were tested using a total of 23 beams as represented in Table 3. Series B 
Table 2. Properties of adhesives (from manufacturer)

\begin{tabular}{lccc}
\hline \multirow{2}{*}{ Material property } & \multicolumn{2}{c}{ Value } & \multirow{2}{*}{ Testing standard } \\
\cline { 2 - 3 } & Resin 1 & Resin 2 & \\
\hline Density $\left(\mathrm{g} / \mathrm{cm}^{3}\right)$ & 1.65 & 1.30 & - \\
\hline Compressive strength $(\mathrm{MPa})$ & $70-95$ & - & EN 196 \\
\hline Shear strength $(\mathrm{MPa})$ & 18 & - & DIN 53283 \\
\hline Tensile strength $(\mathrm{MPa})$ & $24-31$ & 30 & DIN 53455 \\
\hline Tensile modulus of elasticity $(\mathrm{MPa})$ & 11,200 & 4,500 & DIN 53455 \\
\hline
\end{tabular}

consisted of glulam beams with one horizontal CFRP plate bonded to the intrados surface. Series E consisted of glulam beams with one vertical CFRP plate bonded in the slot made in the intrados surface. For the adopted reinforcement schemes, the cross section ratio between the CFRP plate and the glulam beam was $0.46 \%$. Series A unreinforced beams were investigated in order to act as a control series for reinforced beams. Series B had more specimens tested compared to Series E due to their easy preparation and favourable reinforcement effect. Larger number of unreinforced specimens (Series A) was tested because of greater variability associated with their behaviour.

All beams were subjected to bending test in accordance with EN 408:2010. The beams were simply sup- ported (span of $3780 \mathrm{~mm}$ ) and tested in a four-point bending configuration as shown in Table 3 . The load was applied monotonically until failure by a hydraulic jack and recorded with a compression load cell. Roller bearings and steel plates (for minimizing local indentions) were used at both supports and load application points. In order to prevent lateral instability of beams lateral bracing was placed. Linear variable differential transducers (LVDTs) were used for the measurement of deflections of the beams relative to the supports. Strains at mid-span were measured by strain gauges positioned throughout the height of the beams. All readings from strain gauges, LVDTs and loading cell were recorded using a computerized data acquisition system.

Table 3. Geometry of unreinforced and reinforced glulam beams

\begin{tabular}{l} 
Side view and cross section \\
\hline Series A - Beams without reinforcement (8 specimens) \\
\hline
\end{tabular}

Series B - Beams with external CFRP reinforcement (10 specimens)

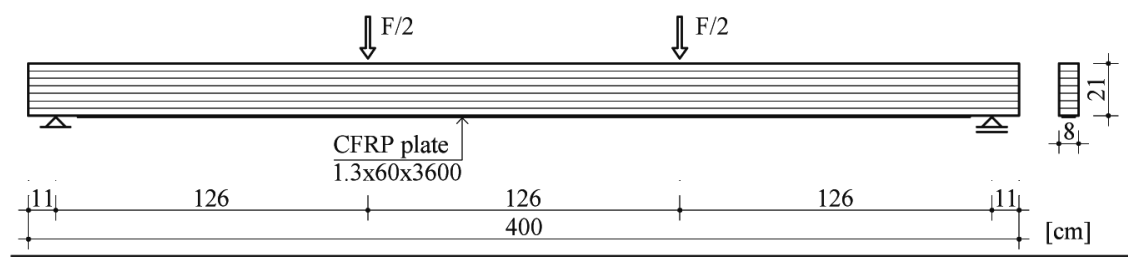

Series E - Beams with internal CFRP reinforcement (5 specimens)

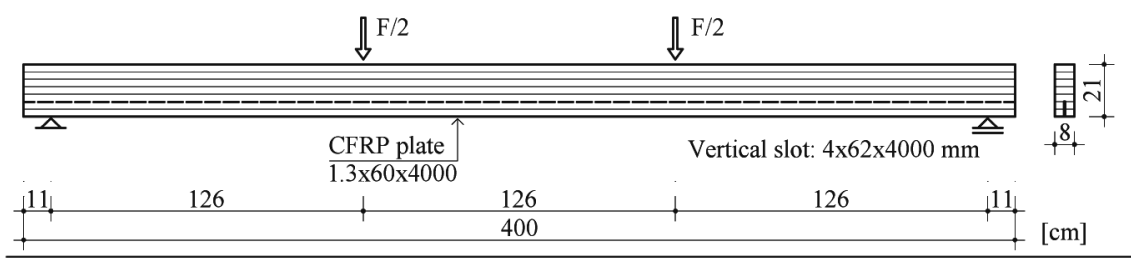



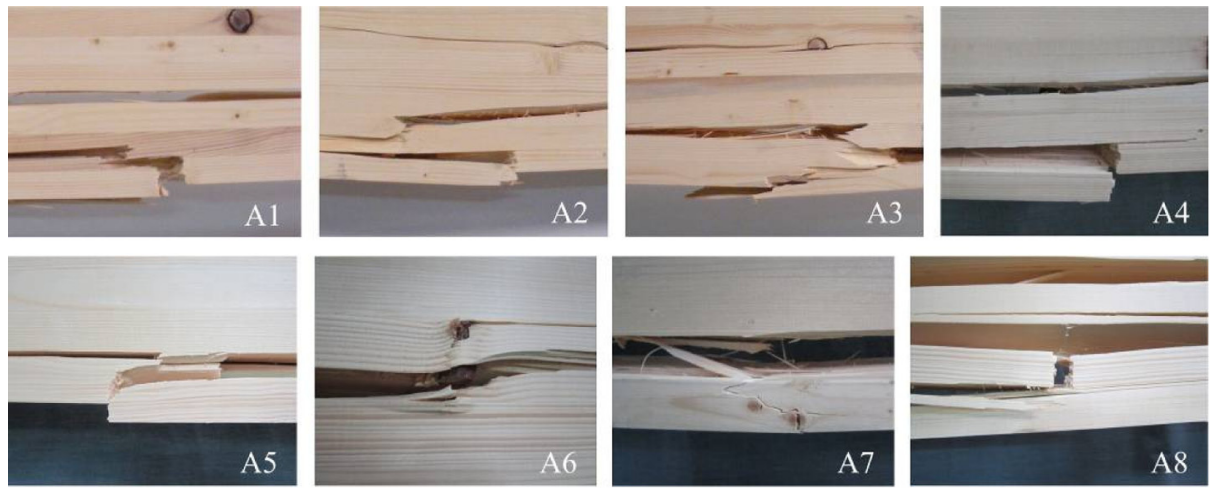

Fig. 1. Failure mechanism of Series A unreinforced beams
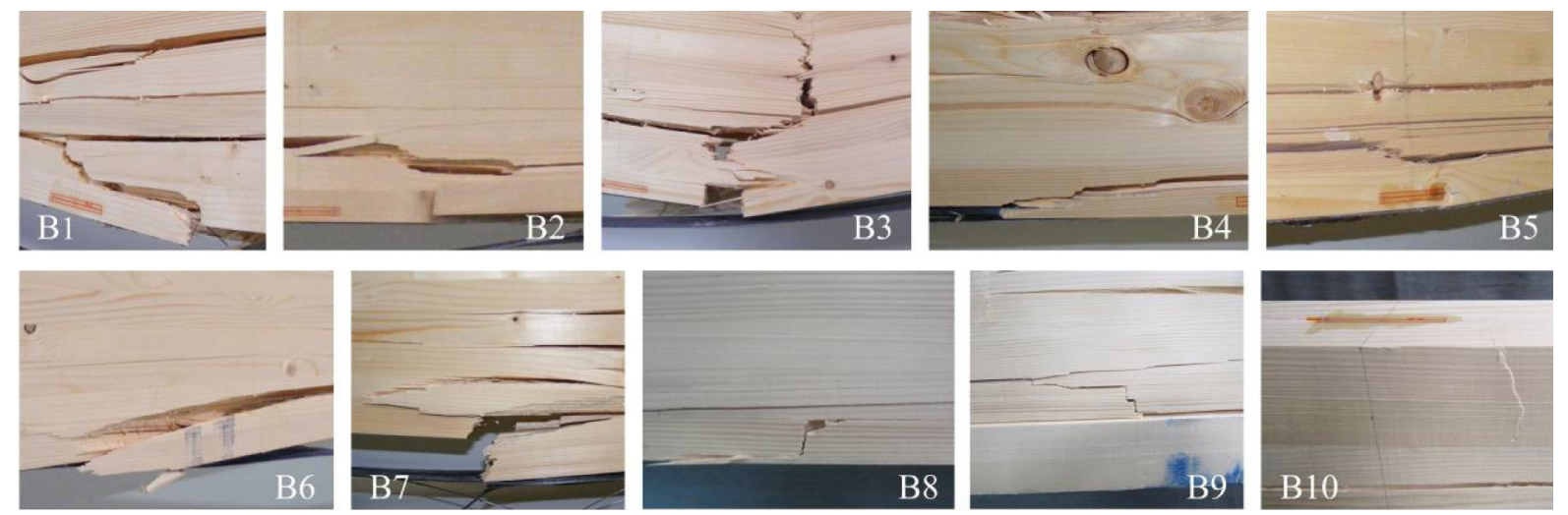

Fig. 2. Failure mechanism of Series B reinforced beams
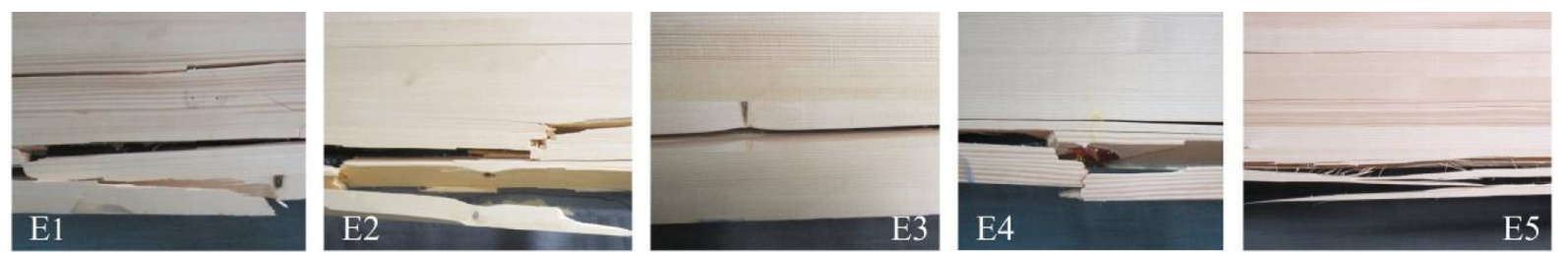

Fig. 3. Failure mechanism of Series E reinforced beams

\subsection{Test results}

Unreinforced beams (Series A) failed in the zone of maximum bending moment between loading points due to excessive tensile stresses in bottom laminations (Fig. 1). Before the failure unreinforced beams showed linear load-deflection behaviour, without compressive plasticization of the top laminations.

Tensile failure, with or without partial plasticisation in compression zone, were noted in Series B reinforced beams. The load-deflection behaviour was linear-elastic until local fractures occurred in the tension zone. Yielding of compressive timber produced a nonlinear response that was ended by a sudden drop of load as a result of tensile failure in timber (Fig. 2). Plasticization in the form of buckled fibres occurred in compression zone, but generally top laminations remained intact. Shear cracks after initial tensile fractures were noticed in the number of beams. Explosive nature of tensile failures in some beams caused detachment of CFRP plates. The adhesion between timber and reinforcement failed only after timber had ruptured.

Series E reinforced beams demonstrated linear behaviour before tensile failure of the bottom laminations (Fig. 3). Plasticization of timber in the compression zone was limited due to early appearance of cracks in tension zone. Bond between CFRP and timber was intact before failure, and reinforcement detached only after timber had ruptured.

The results of experimental tests concerning maximum load, maximum mid-span deflection and elastic stiffness for each beam series are shown in Table 4. In the last column the percentage increase of values relative to the unreinforced beams is given, showing the effect of the reinforcement on the ultimate load carrying capacity, stiffness and deformability. Mechanical performance of beams highly depends on the arrangement of the re- 
Table 4. Experimental results from bending tests

\begin{tabular}{|c|c|c|c|c|c|c|}
\hline $\begin{array}{c}\text { Test } \\
\text { series } \\
\end{array}$ & $\begin{array}{l}\text { Number of } \\
\text { specimens }\end{array}$ & Average & Minimum & Maximum & $\begin{array}{l}\text { Standard } \\
\text { deviation }\end{array}$ & $\begin{array}{c}\text { Percentage } \\
\text { increase (\%) }\end{array}$ \\
\hline \multicolumn{7}{|c|}{ Maximum load $(\mathrm{kN})$} \\
\hline $\mathrm{A}$ & 8 & 37.9 & 32.3 & 45.4 & 4.6 & - \\
\hline $\mathrm{B}$ & 10 & 59.1 & 48.4 & 70.1 & 7.3 & 56.0 \\
\hline $\mathrm{E}$ & 5 & 45.0 & 39.8 & 50.8 & 4.1 & 18.6 \\
\hline \multicolumn{7}{|c|}{ Maximum mid-span deflection (mm) } \\
\hline $\mathrm{A}$ & 8 & 59.9 & 50.5 & 66.7 & 6.0 & - \\
\hline $\mathrm{B}$ & 10 & 93.8 & 71.0 & 123.5 & 17.4 & 56.5 \\
\hline $\mathrm{E}$ & 5 & 74.4 & 61.9 & 89.6 & 11.9 & 24.1 \\
\hline \multicolumn{7}{|c|}{ Bending stiffness $E I\left(\times 10^{11} \mathrm{Nmm}^{2}\right)$} \\
\hline $\mathrm{A}$ & 8 & 6.46 & 5.88 & 7.29 & 0.50 & - \\
\hline B & 10 & 7.73 & 7.20 & 8.31 & 0.38 & 19.5 \\
\hline $\mathrm{E}$ & 5 & 7.18 & 6.82 & 7.77 & 0.39 & 11.1 \\
\hline
\end{tabular}

inforcement in the cross section. In spite of the beams being reinforced, there was no improvement of the variability in results regarding maximum load and maximum mid-span deflection. Explanation can be found in tensile failure of timber, which is sudden, random and violent.

In the case of unreinforced beams strain distribution at mid-span across the height was quite linear until failure, with tensile and compressive strains almost identical at different load levels. As the applied load increased the position of the neutral axis remained the same, proving there was no plasticisation in the compression zone.

For the reinforced beams linear strain distribution across the height was observed in the elastic region. A non-linear strain distribution prior to failure was noticed for the reinforced beams where plastic behaviour in the compression zone was reached. The neutral axis moved towards the beam tension zone due to the contribution of the CFRP plate. There was no significant movement of neutral axis as the applied load was increasing and plasticization in compression zone was occurring. The strain measured on CFRP plate corresponded quite well to the strain measured in the adjacent timber lamination, indicating that there was no noticeable slip between timber and reinforcement.

A considerable improvement in usable strains was seen in reinforced beams. CFRP reinforcement overcame the influences of local defects and fractures in timber, resulting in the increase in ultimate tensile strains. Average ultimate tensile strains in timber for all test series are shown in Table 5 . The strain gauges were unable to record the exact tensile strains of timber in the late loading stages; therefore the tensile strain in outermost wood fibres was estimated from other strain values and linear strain profile. Besides the improvement in tensile strains, addition of the reinforcement causes greater compressive strains, resulting in better utilisation of the capacity of glulam section.
Table 5. Average failure tensile strains in timber

\begin{tabular}{ccc}
\hline $\begin{array}{c}\text { Test } \\
\text { series }\end{array}$ & $\begin{array}{c}\text { Tensile } \\
\text { strain (\%) }\end{array}$ & $\begin{array}{c}\text { Percentage } \\
\text { increase (\%) }\end{array}$ \\
\hline A & 3.68 & - \\
B & 4.59 & 24.8 \\
E & 4.22 & 14.6 \\
\hline
\end{tabular}

\section{Numerical modelling}

\subsection{Model development}

The numerical analysis was performed using the finite element method and the Standard solver of software package ABAQUS (2012). Both unreinforced and reinforced beams were modelled. Geometry and loading arrangements of the model were adopted in accordance with the experimentally tested beams. Due to symmetry, only $1 / 4$ of beam was considered while the removed parts were replaced with appropriate symmetry constraints. The end support was modelled as a roller support which restrained the vertical movement of the beam. The longitudinal translation of the beam was allowed. Timber laminations were modelled as individual parts so that each of their material properties could be included. Perfect bond was assumed to exist between laminations as it was proven by the previous experiments and the phenol-resorcinol adhesive layer was not modelled because of its very small thickness. Also, the connection between epoxy and timber and the connection between epoxy and CFRP was assumed to be perfect because tests proved bonds of high quality. So as to avoid stress concentrations, steel plates at the loading and support points were included with the presumption that there is no slip between them and timber.

All of the elements (timber, CFRP and epoxy) were modelled as C3D8R finite elements (eight-node solid finite elements with reduced integration). Element sizes were adopted based on the mesh discretisation study. Finite element mesh used for the analysis is shown in Figure 4 . The mesh consisted of two finite elements through the thickness of each timber lamination and one element 


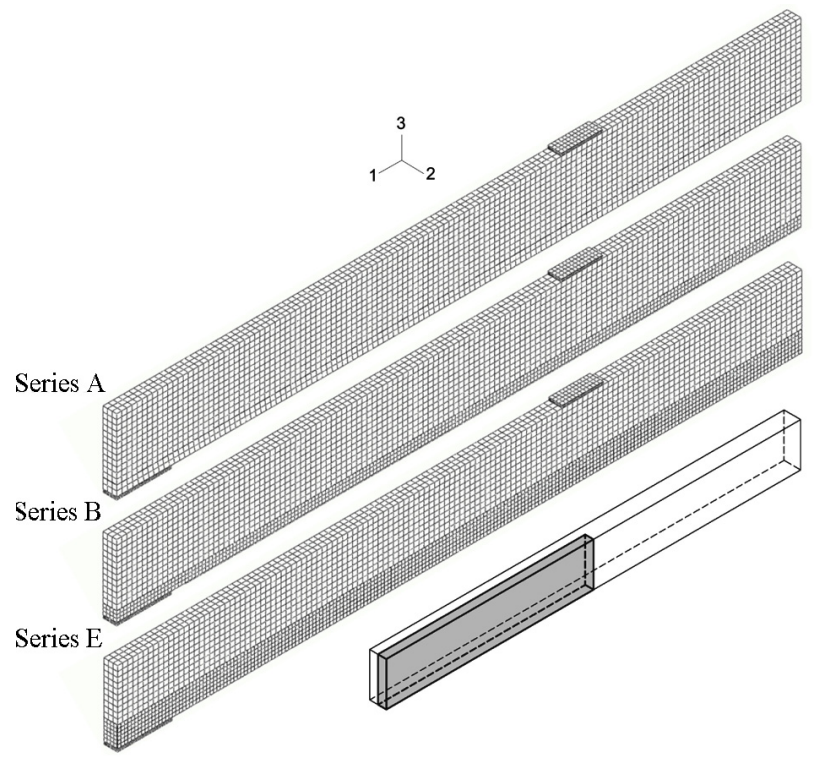

Fig. 4. Mesh discretisation for unreinforced (Series A) and reinforced (Series B and Series E) beams

through the thickness of CFRP and epoxy adhesive layer. Finer mesh was generated for laminations adjacent to the CFRP reinforcement, where stress transfer from CFRP plate to glulam occurs. "Tie constraint" was employed for the bonds between timber laminations and timber/epoxy/ CFRP interfaces.

The static small displacement analysis was performed using a series of vertical displacement increments as a line load over the width of the beam until the established failure condition was reached. Geometrical nonlinearities were taken into account which meant that finite elements in the numerical simulations were always formulated in the current configuration using current nodal positions, with the update of the stiffness matrix of the structure on every increment (Campilho et al. 2009). Maximum stress criterion determined the ultimate load carrying capacity of the beams. Failure in model occurred at a displacement step when the computed tensile stresses in the longitudinal direction reached the tensile strength of the timber lamination. Progressive crack propagation of timber grain was not examined in this study. Since CFRP has high tensile strength and its failure did not occur during the experimental tests, the rapture of the reinforcement was not considered.

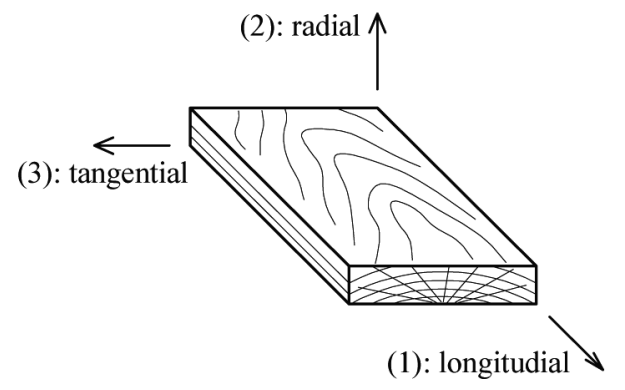

Fig. 5. Local coordinate system for timber

\subsection{Material characterization}

Modelling the materials correctly is the basis of getting accurate results from the numerical analysis. As timber is an organic material, its modelling is very complex. Definition of strength and stiffness for different material directions is required due to the anisotropy of timber. Furthermore, behaviours in tension and compression have to be modelled differently. Also, since timber is inhomogeneous with various growth defects that means that physical and mechanical properties in many cases have to be defined at an element level or cross-section level, rather than at the global material level (Thelandersson 2003). All of the mentioned properties of timber where taken into account during the material modelling.

Not to make the model to complex, timber was considered to be orthotropic material. Figure 5 shows three main anatomical directions of wood that were adopted. Nine independent constants (three modulus of elasticity, three shear modulus and three Poisson's ratios) were used for the description of the mechanical behaviour of timber. A linear-elastic relationship defined the stressstrain behaviour of the timber in tension, while a linear elastic-perfectly plastic relationship was used timber in compression. The constitutive low for timber (Fig. 6) can be expressed by:

$$
\begin{array}{ll}
\sigma_{w, t}=E_{w} \cdot \varepsilon_{w, t} & \\
\sigma_{w, c}=E_{w} \cdot \varepsilon_{w, c} & \text { if } \quad \varepsilon_{w, c} \leq \varepsilon_{w, c y}, \\
\sigma_{w, c}=\sigma_{w, c y} & \text { if } \quad \varepsilon_{w, c}>\varepsilon_{w, c y}
\end{array}
$$

where: $\sigma_{w, t}$ and $\sigma_{w, c}$ are the timber tensile and compressive stress; $E_{w}$ is timber elasticity modulus; $\varepsilon_{w, t}$ and $\varepsilon_{w, c}$ are tensile and compressive strain in timber; and $\varepsilon_{w, c y}$ is strain value at yield stress $\sigma_{w, c y}$. Expected plastic behaviour of top three laminations in compressive zone was modelled using the theory of anisotropic plasticity. The Hill's criterion for orthotropic materials was used as a condition for transition to the plastic state. It represents a generalized version of von Mises' yield criterion which considers the anisotropy of the strength of material (Abrate 2008). Normal compressive yield stresses for the three orthogonal directions as well as yield shear stresses

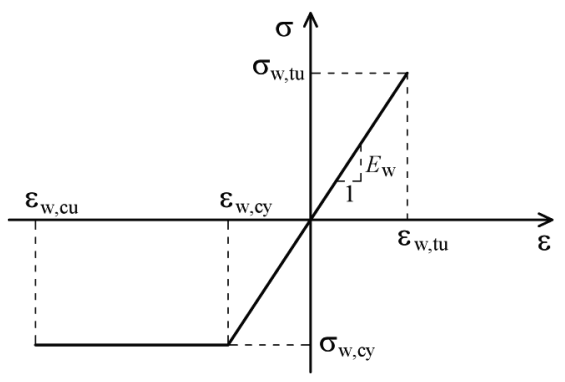

Fig. 6. Constitutive law for timber 
Table 6. Material parameters of timber, CFRP plate and epoxy adhesives used in numerical modelling

\begin{tabular}{|c|c|c|c|c|}
\hline & Timber & CFRP & Resin 1 & Resin 2 \\
\hline \multicolumn{5}{|c|}{ Modulus of elasticity $E(\mathrm{MPa})$} \\
\hline$E_{1}$ & 11,080 & 165,543 & 11,200 & 4,500 \\
\hline$E_{2}$ & 886 & 10,000 & 11,200 & 4,500 \\
\hline$E_{3}$ & 554 & 10,000 & 11,200 & 4,500 \\
\hline \multicolumn{5}{|c|}{ Poisson's ratio $v(-)$} \\
\hline$v_{12}$ & 0.37 & 0.3 & 0.35 & 0.35 \\
\hline$v_{13}$ & 0.42 & 0.3 & 0.35 & 0.35 \\
\hline$v_{23}$ & 0.47 & 0.03 & 0.35 & 0.35 \\
\hline \multicolumn{5}{|c|}{ Shear modulus $G(\mathrm{MPa})$} \\
\hline$G_{12}$ & 791 & 5,000 & - & - \\
\hline$G_{13}$ & 744 & 5,000 & - & - \\
\hline$G_{23}$ & 79 & 1,000 & - & - \\
\hline
\end{tabular}

in the three shear planes were declared to satisfy the criterion.

The CFRP composite was modelled as a liner-elastic anisotropic material with transverse isotropy. Epoxy adhesive and steel were modelled as linear-elastic isotropic materials.

Material characterisation testing, known relationships and data in the available literature were used to define material input parameters. Properties of the materials were assumed to be independent from the loading rates. Relative humidity, temperature, and other environmental factors were not considered in this model. Table 6 shows the material parameters of timber, CFRP plate and epoxy adhesives used in numerical simulations.

The modulus of elasticity of timber $\left(E_{1}\right)$ in the longitudinal direction was determined experimentally. Timber has different moduli of elasticity for tension, compression and bending, but their values are very similar and for practical purposes assumed to be identical. The general relationships proposed by Bodig and Jayne (1982) were used to calculate the moduli in the transverse directions and shear planes:

$$
\begin{gathered}
E_{1}: E_{2}: E_{3} \approx 20: 1.6: 1 ; \\
G_{12}: G_{13}: G_{23} \approx 10: 9.4: 1 ; \\
E_{1}: G_{12} \approx 14: 1,
\end{gathered}
$$

where: $E_{1}, E_{2}, E_{3}$ are the moduli of elasticity in the longitudinal, radial and tangential directions, and $G_{12}, G_{13}$, $G_{23}$ are the shear moduli in the shear orthotropic planes. The values of Poisson's rations $v_{12}, v_{13}, v_{23}$ were adopted based on values given in the literature for softwood (Bodig, Jayne 1982).
The elastic parameters for CFRP plate were adopted based on experimental tests $\left(E_{1}\right)$ as well as values published by Harris (1999). The properties in the plate thickness direction were considered to be the same as those in transverse direction. Adhesive properties (modulus of elasticity and Poisson's coefficient) were taken as given by the manufacturer and by de Castro San Roman (2005).

Selecting values of timber limit stresses presents the most important part of the modelling. The timber tensile stress at failure in bending is greater than stress at failure in axial tension, which was taken into account in material definition. Also, addition of FRP will increase the ultimate tensile stress. For this reason a modification factor was applied for the tensile strength in bending of reinforced timber. Thus:

$$
f_{m r}=\alpha_{m} \cdot f_{m}
$$

where: $f_{m r}$ is the tensile strength in bending of reinforced timber, $\alpha_{m}$ is a modification factor and $f_{m}$ bending strength of timber. A value $\alpha_{m}=1.3$ was proposed by Gentile et al. (2002). This value gave a good agreement with the experimental results for sawn timber beams reinforced with GFRP bars. Based on the ultimate tensile strain data in Table 5, modification factor in this study was adopted as $\alpha_{m}=1.25$ for horizontally positioned reinforcement and $\alpha_{m}=1.15$ for vertically positioned reinforcement.

The yield stresses of timber were taken to be the same as compressive and shear strengths in corresponding directions. Data from other researches were the basis for the estimation of these properties. The assumed yield points are shown in Table 7. For the sake of simplicity, the same values were adopted for radial and tangential directions.

Table 7. Yield points assumed for numerical analysis

\begin{tabular}{ccccccc}
\hline & \multicolumn{5}{c}{ Stress (MPa) } \\
\hline $\bar{\sigma}_{11}$ & $\bar{\sigma}_{22}$ & $\bar{\sigma}_{33}$ & $\bar{\sigma}_{12}$ & $\bar{\sigma}_{13}$ & $\bar{\sigma}_{23}$ \\
\hline 36.3 & 5.0 & 5.0 & 6.1 & 6.1 & 3.0 \\
\hline
\end{tabular}




\section{Results and discussion}

Numerical results were compared with experimental ones in order to verify the proposed numerical model. Figure 7 shows both numerical and test results of all beam series for load-deflection behaviour.

Numerical analysis conducted for unreinforced beams showed linear-elastic behaviour until failure, replicating experimental results very closely. Agreement was also achieved for reinforced beams, including non-linear behaviour before failure which was recorded by both numerical and experimental studies. When beams reinforced at intrados surface are concerned, the model was conservative in predicting the non-linear behaviour.

Table 8 gives numerical results and average experimental results for ultimate load, elastic stiffness and deflection at failure. Numerical analysis confirmed that the addition of the CFRP plate at tension side of the section successfully improves mechanical performance of a glulam beam.
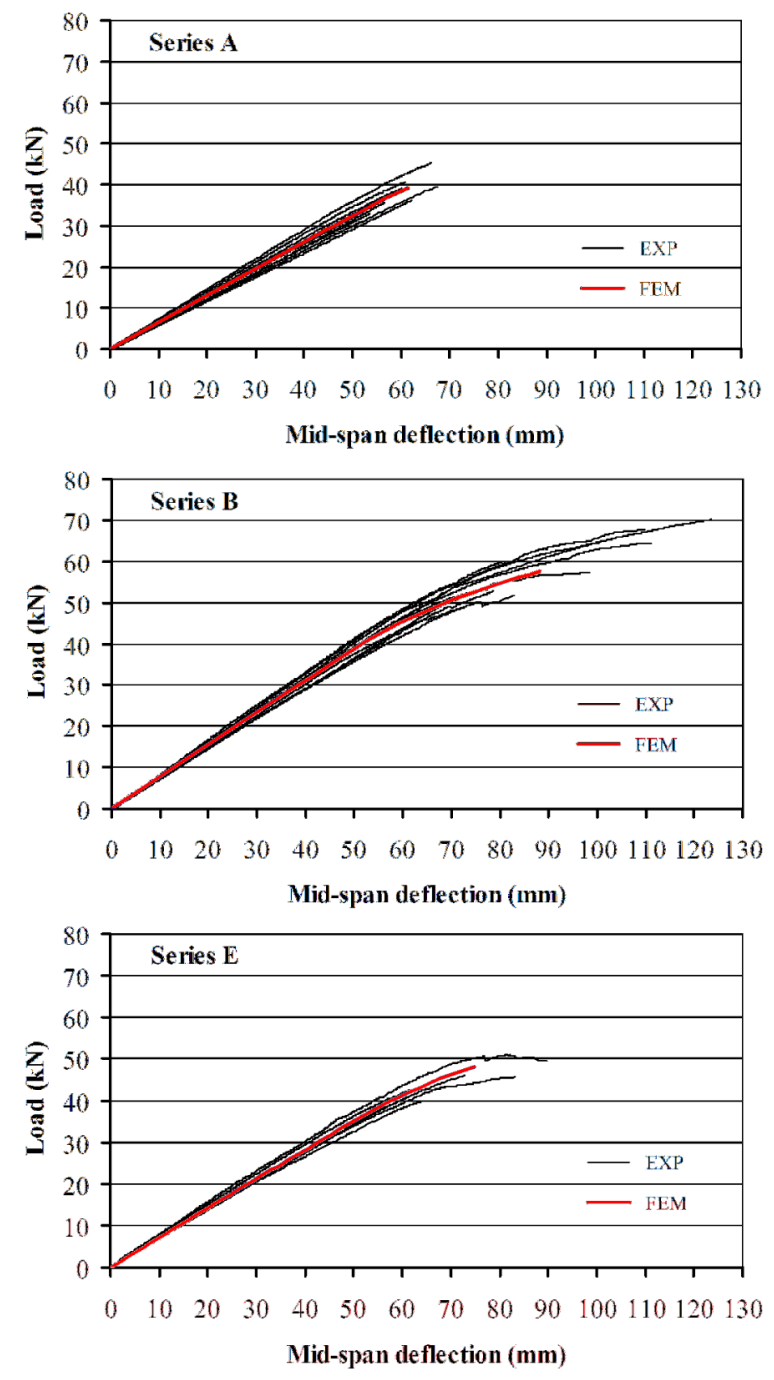

Fig. 7. Load-deflection curves for unreinforced (Series A) and reinforced (Series B and Series E) beams: comparison between experimental tests and numerical modelling
Table 8. Comparison between experimental results and numerical predictions

\begin{tabular}{cccc}
\hline $\begin{array}{c}\text { Test } \\
\text { series }\end{array}$ & Experimental & Numerical & $\begin{array}{c}\text { Numerical/ } \\
\text { Experimental }\end{array}$ \\
\hline \multicolumn{4}{l}{ Maximum load (kN) } \\
\hline A & 37.9 & 39.0 & 1.029 \\
$\mathrm{~B}$ & 59.1 & 57.5 & 0.973 \\
$\mathrm{E}$ & 45.0 & 48.1 & 1.069 \\
\hline \multicolumn{4}{l}{ Maximum mid-span deflection $(\mathrm{mm})$} \\
$\mathrm{A}$ & 59.9 & 61.4 & 1.025 \\
$\mathrm{~B}$ & 93.8 & 88.1 & 0.939 \\
$\mathrm{E}$ & 74.4 & 74.9 & 1.007 \\
\hline Bending stiffness & $E I\left(\times 10^{11} \mathrm{Nmm}^{2}\right)$ & \\
\hline $\mathrm{A}$ & 6.46 & 6.53 & 1.011 \\
$\mathrm{~B}$ & 7.73 & 7.82 & 1.012 \\
$\mathrm{E}$ & 7.18 & 7.08 & 0.986 \\
\hline
\end{tabular}

Theoretical values of ultimate load carrying capacity were based on tensile failure in timber as most common situation. Difference in numerical and experimental results was $3-7 \%$, making the values very close. Since timber has knots and other defects, numerical value of maximum load was higher than experimental for unreinforced beams. In Series B beams the experimental maximum load was higher than the numerical value, which was not the case in Series E beams for which the experimental load was lower than the numerical value. The numerical results for Series B beams are conservative as a result of the used value of modification factor, which should be greater for reinforced timber with CFRP plate positioned on the bottom side. Another possible reason for deviation is the variability of timber bending strength determined during material characterisation testing. The numerical model overestimated the ultimate load carrying capacity of the Series E beams. This can be explained by the fact that longitudinal slot used to insert CFRP plate weakened the beam by disturbing the timber grain, which was not taken into account in numerical modelling.

Numerical prediction of elastic stiffness agreed well with experimental results, with a difference of only $2 \%$. These results prove that timber can be effectively modelled as orthotropic material. The variability of elasticity modulus measurements was the reason for deviation between numerical and test results. Since the agreement of the results is very strong, it is safe to say that the presumption of perfect adhesion between the CFRP and timber was valid.

When mid-span deflection at failure is concerned, numerical and test results were compatible, with noticeable difference of $6 \%$ for Series B beams. In this case the model underestimates the extent of ductile behaviour, which could be an aftermath of variations in compressive strength of timber in the top lamination or the post failure behaviour of some beams during tests. 

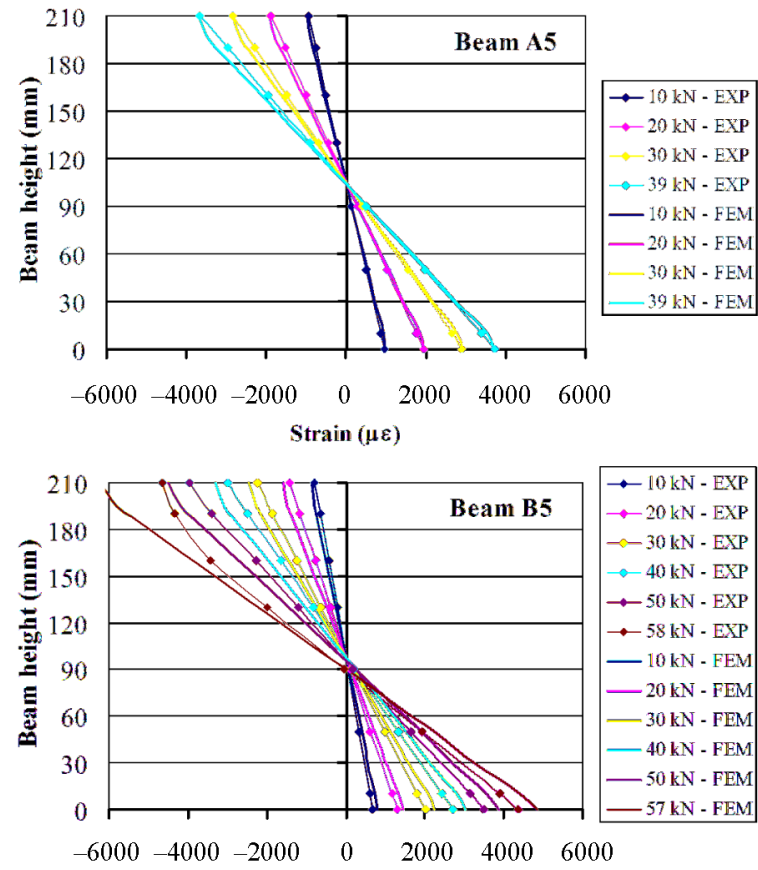

Strain $(\mu \varepsilon)$

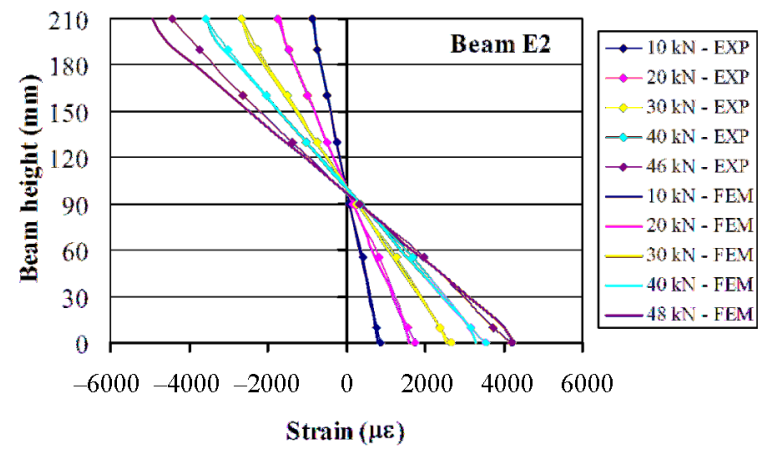

Fig. 8. Strain profiles at different load levels for unreinforced (Series A) and reinforced (Series B and Series E) beams: comparison between experimental tests and numerical modelling

The strain profile distributions at mid-span of beams predicted by the finite element model are illustrated for different load levels in Figure 8. A good indication of the behaviour is achieved from the simulated strain profiles for both unreinforced and reinforced beams. Small differences between numerical and experimental results can be explained by the fact that an average timber modulus of elasticity was used for each entire lamination, while in reality each lamination is inhomogeneous and the material properties of timber vary (Raftery, Harte 2013). Furthermore, a reason for the deviation in the nonlinear region is that the plane section does not remain plane after plastic deformation.

Numerical analysis also gives the patterns of stress distribution inside the test specimens. Figures 9-11 show the contour of normal and shear stresses in glulam at ultimate load for all test series.

Normal stress distribution of unreinforced beams showed that the tension and compression zone are almost the same, while also demonstrating that normal stress increased when the distance from the centre of cross section increased. Thus, the ultimate normal stress was observed at the tensile face. In the case of reinforced beams stress distribution was not uniform, because in the compression zone between the loading points timber started to plasticize with the largest plastic deformation occurring underneath the steel plate for load application. The maximum tensile stress indicated the beginning of splitting, leading to complete failure of beams.

Shear stress in glulam was uniformly distributed in region between support and load application point, in accordance with diagram of shear forces. For reinforced beams maximum shear stresses were concentrated near the loading points, as a consequence of indentation at those positions. This explains combined tensile/shear failure in the case of few tested reinforced beams. In Series $\mathrm{B}$ beams a narrow shear stress peak at the end of the reinforcement was noticed, but this peak was lower than the expected shear strength of timber.

Figure 12 shows the distribution of normal stresses in CFRP plates. It can be seen that stress distribution is quite regular over the entire length. In general, capacity of the CFRP material was utilised in a small degree under working loads. After the compression zone of the glulam beam plasticised the reinforcement was utilised to a greater degree. Numerical results showed that the maximum stresses in CFRP plates at ultimate load of the beams were below $30 \%$ of its tensile strength. A way to

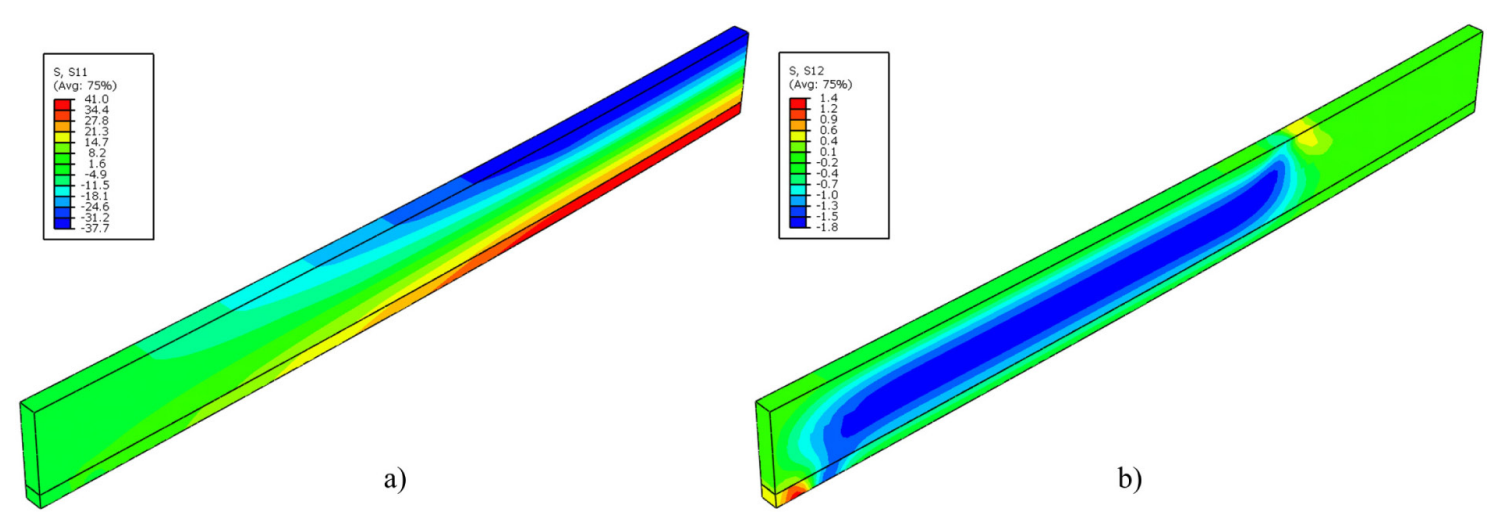

Fig. 9. Stress $(\mathrm{MPa})$ distributions in glulam at ultimate load for Series A beams: a) normal $\sigma_{11}$ stress and b) shear $\sigma_{12}$ stress 

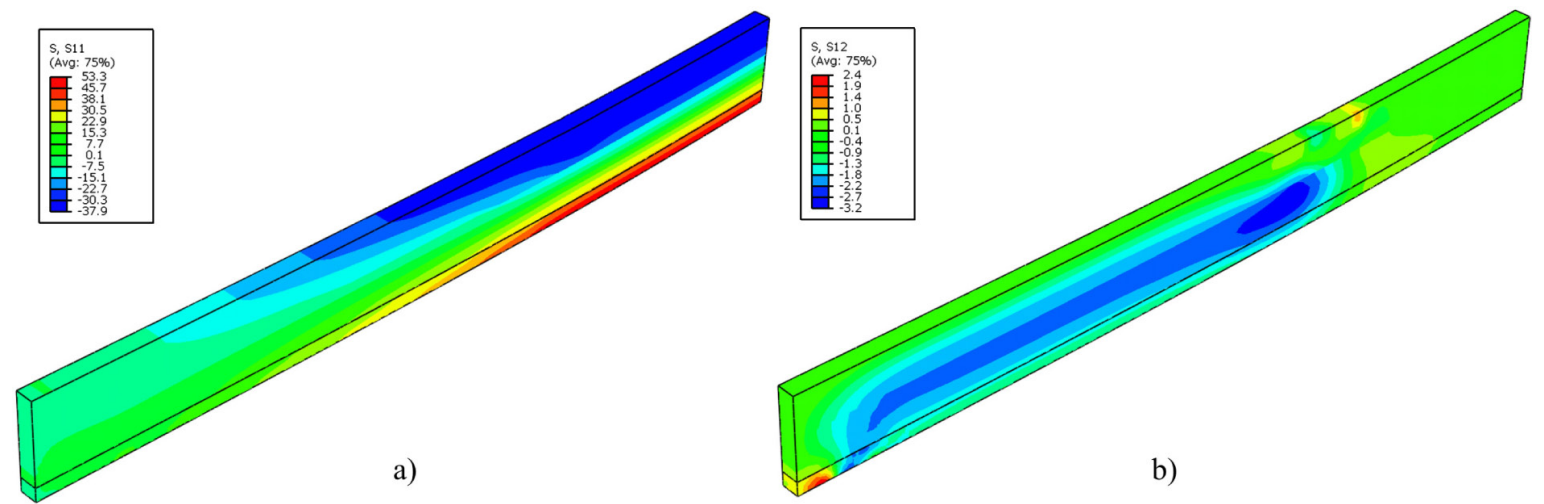

Fig. 10. Stress (MPa) distributions in glulam at ultimate load for Series B beams: a) normal $\sigma_{11}$ stress and b) shear $\sigma_{12}$ stress
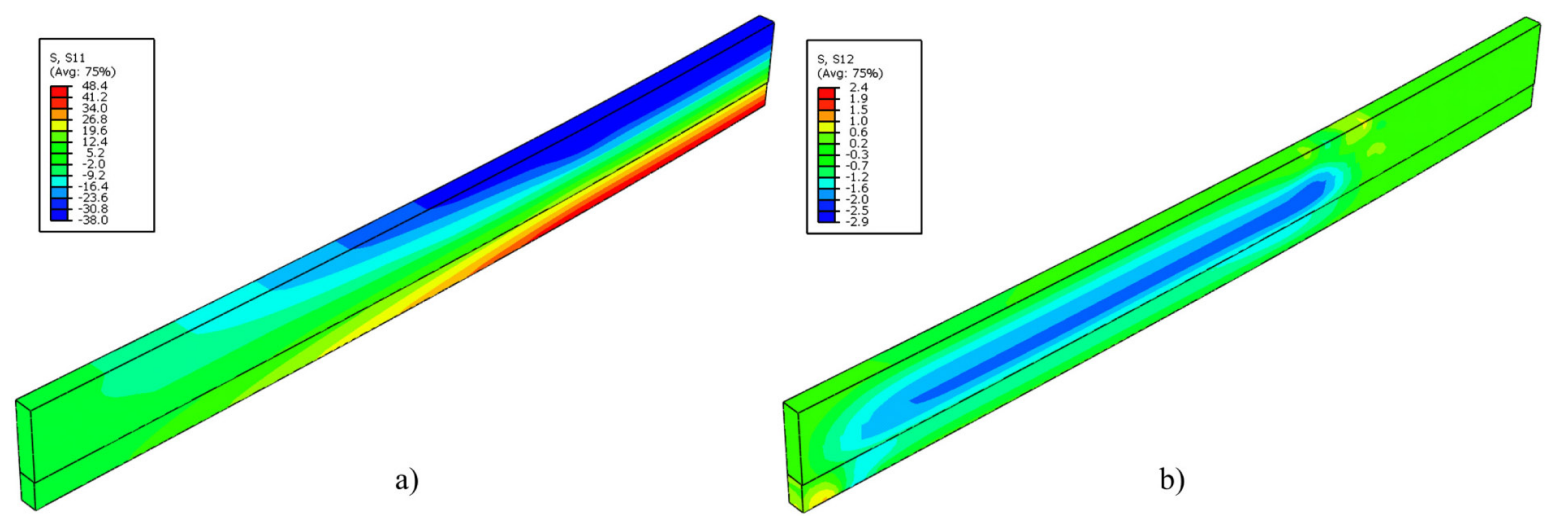

Fig. 11. Stress $(\mathrm{MPa})$ distributions in glulam at ultimate load for Series E beams: a) normal $\sigma_{11}$ stress and b) shear $\sigma_{12}$ stress

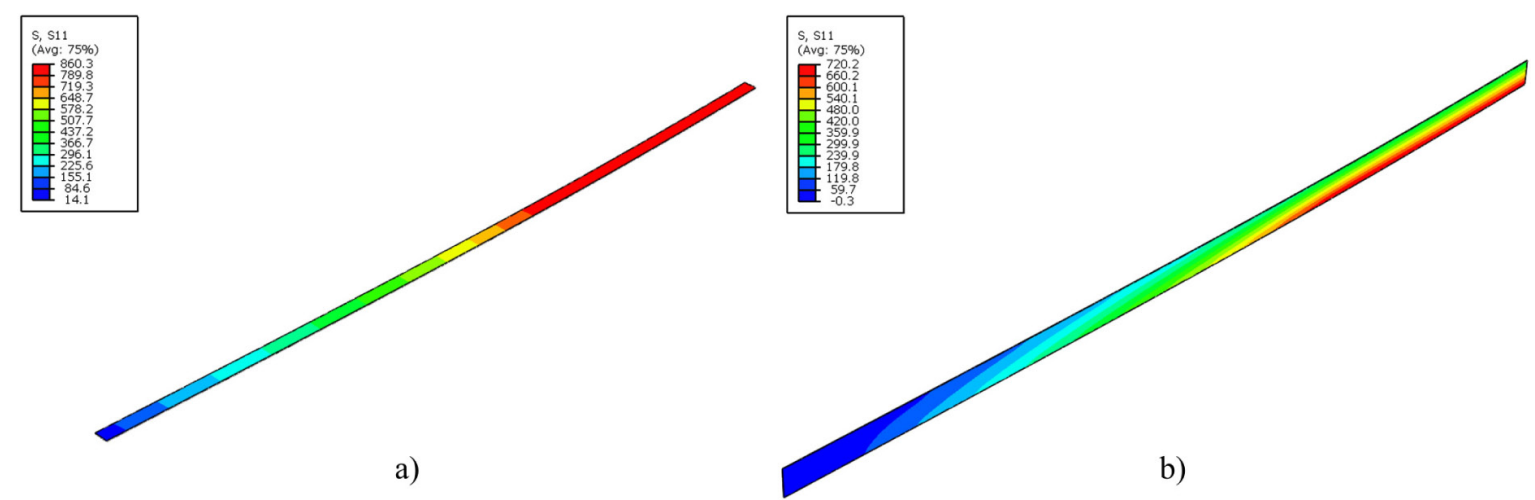

Fig. 12. Normal $\sigma_{11}$ stress (MPa) distributions in CFRP plate at ultimate load: a) for Series B beams and b) for Series E beams

exploit the full capacity of the CFRP material is to use pre-stressing of plate before bonding to tension side of flexural member (Schober et al. 2015).

Numerical analysis was also utilised for the investigation of the mechanical behaviour of bonded joint. In order to make sure that there will be no debonding under load, interfacial stresses created in the adhesive layer between the CFRP plate and glulam should not exceed ultimate values. Experience has shown that externally bonded reinforcement is prone to delamination, which dictates the failure load of reinforced beams (de Jesus et al. 2012). Shear stress distribution along the glue line for ultimate load of Series B beams is presented in Figure 13 and it can be seen that it is not uniform. The maxi- mum value of shear stress was reached at the end of the reinforcement, but it was $4.3 \mathrm{MPa}$ which is significantly lower than the shear capacity of the adhesive $(18 \mathrm{MPa})$.

\section{Conclusions}

A nonlinear finite element model was created for analysing bending behaviour of glulam beams reinforced with CFRP plates. The model was based on elasto-plastic and orthotropic characteristics, Hill's plasticity criterion and perfect bond between CFRP and timber. Previously obtained experimental results confirmed numerical predictions. The following conclusions have been made:

- Numerical modelling was shown to be effective in analysing bending behaviour of unreinforced and 


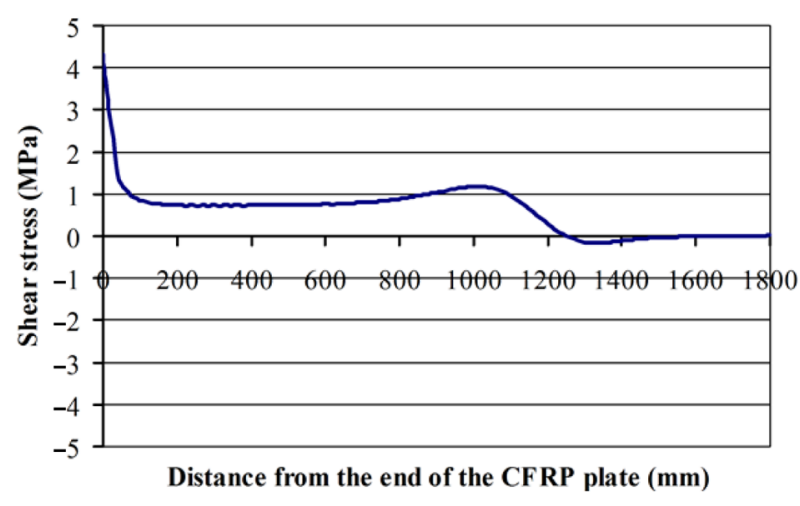

Fig. 13. Shear stress distribution in adhesive layer at ultimate load for Series B beams

reinforced beams, saving resources required for experimental testing.

- Numerically obtained load-deflection curves agreed quite well with experimentally obtained ones. The model has the ability to predict the nonlinear performance of the reinforced beams accurately.

- Good correlation between numerical and experimental data was found for elastic stiffness, ultimate load and mid-span deflection at failure. The numerical results proved that adding the CFRP plate at tensile side of the section improved the ultimate load carrying capacity, stiffness and ductility of glulam beams. Furthermore, the model predicted the strain profile distribution of unreinforced and reinforced beams adequately.

- Modelling the material properly is very important for ensuring the correct results from the numerical analysis. It has to be taken into account that the introduction of CFRP reinforcement could increase tensile failure strain and strength of timber. Based on the experimental results a modification factor $\alpha_{m}$ was suggested in this study. However, type and arrangement of reinforcement and timber grade effects on this factor still need to be examined thoroughly.

- Stress states in glulam and reinforcement can be better understood thanks to numerical analysis. Results from the finite element model showed that the effects of the reinforcement are not only local, but that the addition of CFRP plate has an influence on stress distribution on a global level. Maximum stresses results revealed that only a small percentage of strength capacity of CFRP material was employed.

- The model was also utilised for the analysis of stresses at the interface between CFRP plate and timber. The shear stress distribution in the adhesive layer demonstrated the existence of pronounced anchorage zone towards the end of the reinforcement.

- In order to optimise the design of timber beams reinforced with FRP composites the presented model can easily be modified to different loading configurations, geometrical arrangements or material properties.

\section{References}

ABAQUS. 2012. User's manual, Version 6.12. Pawtucket, Rhode Island: Hibbitt, Karlsson and Sorensen, Inc.

Abrate, S. 2008. Criteria for yielding or yailure of cellular materials, Journal of Sandwich Structures and Materials 10(1): 5-51. https://doi.org/10.1177/1099636207070997

Alhayek, H.; Svecova, D. 2012. Flexural stiffness and strength of GFRP-reinforced timber beams, Journal of Composites for Construction 16(3): 245-252. https://doi.org/10.1061/(ASCE)CC.1943-5614.0000261

Bodig, J.; Jayne, B.A. 1982. Mechanics of wood and wood composites. New York: Van Nostrand Reinhold Company Inc.

Borri, A.; Corradi, M.; Grazini, A. 2005. A method for flexural reinforcement of old wood beams with CFRP materials, Composites Part B: Engineering 36(2): 143-153. https://doi.org/10.1016/j.compositesb.2004.04.013

Borri, A.; Corradi, M.; Speranzini, E. 2013. Reinforcement of wood with natural fibers, Composites Part B: Engineering 53: 1-8.

https://doi.org/10.1016/j.compositesb.2013.04.039

Campilho, R. D. S. G.; de Moura, M. F. S. F.; Barreto, A. M. J. P.; Morais, J. J. L.; Dominguese, J. J. M. S. 2009. Fracture behaviour of damaged wood beams repaired with an adhesively-bonded composite patch, Composites Part A: Applied Science and Manufacturing 40(6-7): 852-859. http://dx.doi.org/10.1016/j.compositesa.2009.04.007

de Castro San Roman, J. 2005. Experiments on epoxy, polyurethane and ADP adhesives. Technical report CCLab2000.1b/1. The Swiss Fedral Institute of Technology of Lausanne.

de la Rosa, G. P.; Cobo, E. A.; Gonzalez, G. M. N. 2013. Bending reinforcement of timber beams with composite carbon fiber and basalt fiber materials, Composites Part B: Engineering 55: 528-536. https://doi.org/10.1016/j.compositesb.2013.07.016

D’Ambrisi, A.; Focacci, F.; Luciano, R. 2014. Experimental investigation on flexural behavior of timber beams repaired with CFRP plates, Composite Structures 108(1): 720-728. https://doi.org/10.1016/j.compstruct.2013.10.005

Dourado, N.; Pereira, F. A. M.; de Moura, M. F. S. F.; Morais, J. J. L. 2012. Repairing wood beams under bending using carbon-epoxy composites, Engineering Structures 34: 342-350. https://doi.org/10.1016/j.engstruct.2011.09.001

EN 338:2009 Structural timber - Strength classes. European standard.

EN 384:2010 Structural timber-Determination of characteristic values of mechanical properties and density. European standard.

EN 408:2010 Timber structures - Structural timber and glued laminated timber - Determination of some physical and mechanical properties. European standard.

EN ISO 527-5:2009. Plastics - Determination of tensile properties. European standard.

Fiorelli, J.; Dias, A. A. 2011. Glulam beams reinforced with FRP externally-bonded: theoretical and experimental evaluation, Materials and Structures 44(8): 1431-1440. https://doi.org/10.1617/s11527-011-9708-y

Fossetti, M.; Minafo, G.; Papia, M. 2015. Flexural behaviour of glulam timber beams reinforced with FRP cords, Construction and Building Materials 95: 54-64. https://doi.org/10.1016/j.conbuildmat.2015.07.116

Galloway, T. L.; Fogstad, C.; Dolan, C. W.; Puckett, J. A. 1996. Initial tests of kevlar prestressed timber beams, in National Conference on Wood Transportation Structures, 23-25 October 1996, Medison, Wisconsin, USA, 215-224.

Gentile, C.; Svecova, D.; Rizkalla, S. H. 2002. Timber beams strengthened with GFRP bars: development and applications, Journal of Composites for Construction 6(1): 11-20. https://doi.org/10.1061/(ASCE)1090-0268(2002)6:1(11) 
Glisović, I.; Stevanović, B.; Todorović, M. 2016. Flexural reinforcement of glulam beams with CFRP plates, Materials and Structures 49(7): 2841-2855. https://doi.org/10.1617/s11527-015-0690-7

Guan, Z. W.; Rodd, P. D.; Pope, D. J. 2005. Study of glulam beams pre-stressed with pultruded GRP, Computers and Structures 83: 2476-2487. https://doi.org/10.1016/j.compstruc.2005.03.021

Harris, B. 1999. Engineering composite materials. London: The Institute of materials.

de Jesus, A. M. P.; Pinto, J. M. T.; Morais, J. J. L. 2012. Analysis of solid wood beams strengthened with CFRP laminates of distinct lengths, Construction and Building Materials 35: 817-828. https://doi.org/10.1016/j.conbuildmat.2012.04.124

Khelifa, M.; Celzard, A. 2014. Numerical analysis of flexural strengthening of timber beams reinforced with CFRP strips, Composite Structures 111(1): 393-400. https://doi.org/10.1016/j.compstruct.2014.01.011

Khelifa, M.; Auchet, S.; Meausoone, P. J.; Celzard, A. 2015. Finite element analysis of flexural strengthening of timber beams with carbon fibre-reinforced polymers, Engineering Structures 101: 364-375.

https://doi.org/10.1016/j.engstruct.2015.07.046

Kim, Y. J.; Harries, K. A. 2010. Modeling of timber beams strengthened with various CFRP composites, Engineering Structures 32(10): 225-3234. https://doi.org/10.1016/j.engstruct.2010.06.011

Kim, Y. J.; Hossain, M.; Harries, K. A. 2013. CFRP strengthening of timber beams recovered from a 32 year old quonset: Element and system level tests, Engineering Structures 57: 213-221. https://doi.org/10.1016/j.engstruct.2013.09.028

Kliger, R.; Haghani, R.; Brunner, M.; Harte, A. M.; Schober, K. U. 2016. Wood-based beams strengthened with FRP laminates: improved performance with pre-stressed systems, European Journal of Wood and Wood Products 74: 319330. https://doi.org/10.1007/s00107-015-0970-5

Micelli, F.; Scialpi, V.; La Tegola, A. 2005. Flexural reinforcement of glulam timber beams and joints with carbon fiberreinforced polymer rods, Journal of Composites for Construction 9(4): 337-347. https://doi.org/10.1061/(ASCE)1090-0268(2005)9:4(337)

Nowak, T. P.; Jasienko, J.; Czepizak, D. 2013. Experimental tests and numerical analysis of historic bent timber elements reinforced with CFRP strips, Construction and Building Materials 40: 197-206. https://doi.org/10.1016/j.conbuildmat.2012.09.106

Oudjene, M.; Khelifa, M. 2009. Finite element modelling of wooden structures at large deformations and brittle failure prediction, Materials and Design 30(10): 4081-4087. https://doi.org/10.1016/j.matdes.2009.05.024

Raftery, G. M.; Harte, A. M. 2011. Low-grade glued laminated timber reinforced with FRP plate, Composites Part B: Engineering 42: 724-735.

https://doi.org/10.1016/j.compositesb.2011.01.029
Raftery, G. M.; Harte, A. M. 2013. Nonlinear numerical modelling of FRP reinforced glued laminated timber, Composites Part B: Engineering 52: 40-50.

https://doi.org/10.1016/j.compositesb.2013.03.038

Raftery, G. M.; Whelan, C. 2014. Low-grade glued laminated timber beams reinforced using improved arrangements of bonded-in GFRP rods, Construction and Building Materials 52: 209-220. https://doi.org/10.1016/j.conbuildmat.2013.11.044

Raftery, G. M.; Kelly, F. 2015. Basalt FRP rods for reinforcement and repair of timber, Composites Part B: Engineering 70: 9-19. https://doi.org/10.1016/j.compositesb.2014.10.036

Schober, K. U.; Rautenstrauch, K. 2007. Post-strengthening of timber structures with CFRP's, Materials and Structures 40(1): 27-35. https://doi.org/10.1617/s11527-006-9128-6

Schober, K. U.; Harte, A. M.; Kliger, R.; Jockwer, R.; Xu, Q.; Chen, J. F. 2015. FRP reinforcement of timber structures, Construction and Building Materials 97: 106-118. https://doi.org/10.1016/j.conbuildmat.2015.06.020

Sika AG. 2013. Sika CarboDur plates: Pultruded carbon fibre plates for structural strengthening. Product Data Sheet [online], [cited 10 May 2017]. Available from Internet: http://www.sika.com

Sika AG. 2014a. Sikadur-30: Adhesive for bonding reinforcement. Product Data Sheet [online], [cited 10 May 2017]. Available from Internet: http://www.sika.com

Sika AG. 2014b. Sikadur-330: 2-part epoxy impregnation resin. Product Data Sheet [online], [cited 10 May 2017]. Available from Internet: http://www.sika.com

Svecova, D.; Eden, R. J. 2004. Flexural and shear strengthening of timber beams using glass fibre reinforced polymer bars - an experimental investigation, Canadian Journal of Civil Engineering 31(1): 45-55. https://doi.org/10.1139/103-069

Thelandersson, S. 2003. Introduction: safety and serviceability in timber engineering. Chapter 10, in S. Thelandersson, H. J. Larsen (Eds.). Timber engineering. Chichester, England: John Wiley and Sons, Ltd., 171-176.

Triantafillou, T. C. 1998. Strengthening of structures with advanced FRPs, Progress in Structural Engineering and Materials 1: 126-134. https://doi.org/10.1002/pse.2260010204

Yahyaei-Moayyed, M.; Taheri, F. 2011. Experimental and computational investigations into creep response of AFRP reinforced timber beams, Composite Structures 93(2): 628628. https://doi.org/10.1016/j.compstruct.2010.08.017

Yang, H.; Liu, W.; Lu, W.; Zhu, S.; Geng, Q. 2016a. Flexural behavior of FRP and steel reinforced glulam beams: Experimental and theoretical evaluation, Construction and Building Materials 106: 550-563.

hhttps://doi.org/10.1016/j.conbuildmat.2015.12.135

Yang, H.; Ju, D.; Liu, W.; Lu, W. 2016b. Prestressed glulam beams reinforced with CFRP bars, Construction and Building Materials 109: 73-83. Available at: https://doi.org/10.1016/j.conbuildmat.2016.02.008

Ivan GLIŠOVIĆ. Assistant Professor at the Department of Materials and Structures, Faculty of Civil Engineering, University of Belgrade. Field of research: timber and masonry structures.

Marko PAVLOVIĆ. Assistant Professor at the Department of Structural Engineering, Faculty of Civil Engineering and Geosciences, Delft University of Technology. Field of research: steel and composite structures.

Boško STEVANOVIĆ. Full Professor at the Department of Materials and Structures, Faculty of Civil Engineering, University of Belgrade. Field of research: timber, composite timber-concrete and masonry structures.

Marija TODOROVIĆ. PhD student, Teaching Assistant at the Department of Materials and Structures, Faculty of Civil Engineering, University of Belgrade. Field of research: timber and masonry structures. 